\title{
The Prognostic Value of DWI MRI in the Diagnosis of Soft Tissue Sarcomas
}

\author{
Medhat M. Refaat, Shorouk Z. Abdelshafy, Asmaa H. Mohamed
}

\begin{abstract}
Department of Diagnostic and Interventional Radiology Faculty of Medicine Benha University, Egypt.

Correspondence to: Asmaa H. Mohamed, Department of Diagnostic and Interventional Radiology Faculty of Medicine Benha University, Egypt
\end{abstract}

Email:

asmaahamdibenha@gmail.com

Received: 20 October 2020

Accepted: 8 August 2021

\begin{abstract}
Background: DWI is beneficial in evaluation of soft tissue sarcomas, thus improving the diagnostic accuracy, characterization and response to treatment. Purpose: The aim of this study was to evaluate the benefit of using quantitative diffusion-weighted imaging (DWI) with apparent diffusion coefficient (ADC) mapping in the diagnosis of soft
\end{abstract} tissue sarcoma, with emphasis on its prognostic value. Patients and Methods: This study included 50 patients with pathologically proven soft tissue sarcoma. The DWI was obtained with $3 \mathrm{~b}$ values, including 0,400 , and $800 \mathrm{~s} / \mathrm{mm}^{2}$. Calculation of the ADC value of the lesion was done by placing the region of interest (ROI) to include the largest area of the lesion. ADC values were compared with the histopathology. Results: The most frequent site was thigh (48.0), followed by shoulder, forearm, arm and foot (8.0\% for each). The most frequent pathology was synovial sarcoma $(32.0 \%)$ followed by spindle cell sarcoma $(28.0 \%)$ then liposarcoma $(12.0 \%)$. $80 \%$ of lesions showed restricted diffusion. Median ADC value was 0.7 and ranged from 0.5 to 2.4. All patients underwent surgery, $48.0 \%$ of patients received chemotherapy and $52.0 \%$ received radiotherapy. $56.0 \%$ of patients showed recurrence, while $44.0 \%$ showed metastasis. Mean follow up duration was 13 months with standard deviation of 5 months. Median ADC value was significantly higher in patients with no recurrence (0.9) compared to those with recurrence $(0.7)$. $\mathrm{P}$ value was 0.016. Conclusion: DWI with ADC mapping of soft tissue sarcoma has additive role to anatomic sequences for lesion characterization and grading as well as treatment response.

Keywords: DWI; MRI; Sarcoma 


\section{Introduction:}

Soft tissue sarcoma is a heterogeneous group of malignant neoplasms that often shows a high mortality rate ${ }^{(1)}$. They are rare malignancies of connective tissues that arise from mesenchymal precursors mainly in the extremities and comprise about $1 \%$ of cancers in adults ${ }^{(2,3)}$.

They include at least 100 different histologic and molecular subtypes, with each subtype having variable clinical behavior ${ }^{(4)}$.

Magnetic resonance imaging is the most widely used tool for the detection of soft tissue sarcoma and determination of tumor extent, pre operatively ${ }^{(5,6)}$.

Contrast in soft tissues is of higher quality allowing an easier detection of the lesion, and improves delineation of their extent and involvement of neurovascular structures and medullary bone ${ }^{(7)}$.

Diffusion-weighted imaging (DWI) is a rapid, non-contrast magnetic resonance (MR) technique. DWI provides information about the extracellular Brownian motion of water molecules in a tissue examined (true diffusion), as well as its microcirculation (perfusion). Hence, tissues with increased cellularity led to decreased Brownian motion or restricted diffusion, while tissues with decreased cellularity have unrestricted or increased diffusion ${ }^{(8,9)}$.

The apparent diffusion coefficient (ADC) value, representing a combination of both true diffusion and perfusion, is a numerical value express degree of movement in a tissue and has been used as a marker for cellularity in soft tissue imaging ${ }^{(9)}$.

Unlike morphological MR imaging sequences and DCE, adds functional information about tissue composition without intravenous contrast administration (10).

Diffusion-weighted imaging is routinely used in several clinical scenarios. Besides still being a hot research topic, it has been tested in almost all cancers to differentiate malignant from benign lesions, and to distinguish different malignant histological types or tumor grades, to predict and/or assess treatment responses, as well as to identify residual or recurrent tumors in follow-up examinations ${ }^{(11)}$.

\section{Patients and methods:}

This was a cohort which included 50 patients (30 females and 20 males) referred to MRI Unit, Damanhour Oncology center 
for MRI evaluation of soft tissue tumors that further proved pathologically to be soft tissue sarcomas. This study included clinically suspected soft tissue sarcomas with no age or sex predilection. Patients with contraindication to MRI (e.g.: patients who have heart pacemaker, metallic foreign body and metallic device) and patients with severe claustrophobia were excluded. An informed consent from all patients was taken before the MRI examination. Further follow up of these patients were done including management they received either surgery, $\mathrm{CTH}$ or RTH and if recurrence occurred or metastasis. This study was done in the time from December 2017 to April 2020. The study was approved by the institutional ethics committee.

\section{MRI technique:}

Patients were examined using 1.5 T closed MRI machine (MR system, GE, SIGNA) using the most optimal surface coil accommodates each lesion. The predetermined examination protocol was applied to all patients that included the following:

- $\quad$ T1-WI $(\mathrm{TR} / \mathrm{TE}=$ 400-700/14-30; FOV, 20-35 cm) in axial, coronal and/or sagittal.

- $\mathrm{T} 2-\mathrm{WI}(\mathrm{TR} / \mathrm{TE}=2800-4500 / 80-120$;

FOV, 20-35 cm) in axial and coronal
- Fat suppression sequence or short tau inversion recovery (STIR) sequence in axial and coronal planes $(\mathrm{TR} / \mathrm{TE}=$ 4000-5600/18-40;FOV, 20-35 cm) or PD FS (2000-2500/20-40; FOV, 20-35 $\mathrm{cm})$ in sagittal \& coronal view.

- Post IV contrast study (FAT saturation T1WI sequences-in most cases). We use typical contrast medium-based intravenous agents, gadopentate dimeglumine (Magnevist; Schering, Berlin, Germany); at a dose of 0.1 $\mathrm{mmol} / \mathrm{kg}$

- Diffusion weighted MR images were taken in the axial plane by single shot, (EPI) imaging sequence : (TR 80008500 msec., TE50-60 m sec, 5 mm slice thickness, $1 \mathrm{~mm}$ slice spacing, FOV25$30 \mathrm{~cm})$. The strength of Motion Probing Gradient (MPG) is defined by the gradient factor b. The b-values used were 0,400 and $800 \mathrm{~s} / \mathrm{mm} 2$.

The ADC is numerical value calculated by manually placing a region of interest (ROI) over the solid portion of tumor. The MR imaging results were correlated with the histopathological examination and statistical analysis of the collected data. 


\section{ADC calculation}

- The section with the largest tumor diameter was selected for ADC calculation including the visibly most restricted diffusion area on the ADC map, with the region of interest (ROI) being large as possible. Measurements were recorded as a representative value for each case.

\section{Interpretation of diffusion-weighted images}

- The lesion was determined on DWI and ADC map by using the conventional MR images as a guide.

- The signal intensity of the lesion on DWIs was determined.

- $\mathrm{ADC}$ of the minimum, maximum, and average values was obtained.

\section{Statistical analysis:}

Data management and statistical analysis were done using SPSS vs.25. (IBM, Armonk, New York, United states).Numerical data was summarized as means and standard deviations or medians and ranges. Categorical data was summarized as numbers and percentages.

All $\mathrm{P}$ values were two sided. $\mathrm{P}$ values less than 0.05 were considered significant.

\section{Results:}

This study included 50 patients, 30 females (60\%) and 20 males (20\%) (Fig.1), regarding in age between 20 and 63 years (mean age: $42+12$ ).

The most frequent site was thigh (48.0), followed by shoulder, forearm, arm and foot (8.0\% for each) (Fig. 2).

The diagnosis was confirmed after the MRI examination by the histologic biopsy according to standard histopathological procedures in all cases. From the 50 soft tissue mass lesions, cases were synovial sarcoma 16 cases $(32.0 \%), 14$ cases were spindle cell sarcoma (28), 6 cases were liposarcoma (12\%), 4 cases were cavernous Hemangioma (6.7\%), 2 cases were hemangioma $(6.7 \%), 2$ cases were fibromyxosarcoma (8\%), 2 cases were clear cell sarcoma (4\%),2 cases were Dermatofibrosarcoma protuberance (4\%), 2 cases were pleomorphic sarcoma (4\%),2 cases were PNET (4\%),2 cases were undifferentiated sarcoma (4\%) (Fig. 3).

In our study $80 \%$ of lesions showed restricted diffusion. Median ADC value was $0.7 \times 10^{-3} \mathrm{~mm}^{2}$ and ranged from 0.5 to $2.4 \mathrm{x}$ $10^{-3} \mathrm{~mm}^{2}$ (Table 1).

All patients underwent surgery, $48.0 \%$ of patients received chemotherapy and $52.0 \%$ received radiotherapy (Fig. 4). 
Table 2 showed that $56.0 \%$ of the patients showed recurrence, while $44.0 \%$ showed metastasis. Mean follow up duration was 13 months with standard deviation of 5 months. Table 3 showed that median ADC value was significantly higher in patients with no recurrence (0.9) compared to those with recurrence (0.7). P value was 0.016 .

\section{Case 1 (Fig. 5)}

A -26 - year old male patient presented with a painless swelling at the medial aspect of the right lower thigh proved pathologically to be myxoid liposarcoma. This patient was managed the right upper thigh proved pathologically to be Biphasic synovial sarcoma.

This patient was managed by surgery and received $R T H$ yet he had local recurrence with lung and inguinal nodal metastasis.

\section{Case 2 (Fig. 6)}

A -55 - year old male patient presented with a small painless swelling at the posterior aspect of only by surgery and for 1 year no recurrence occurred.

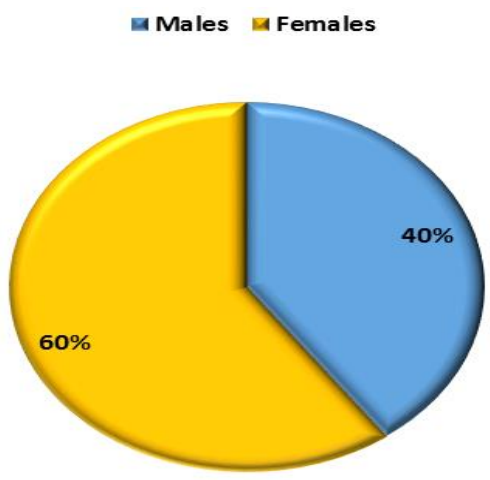

Figure 1: Sex distribution of the study group.

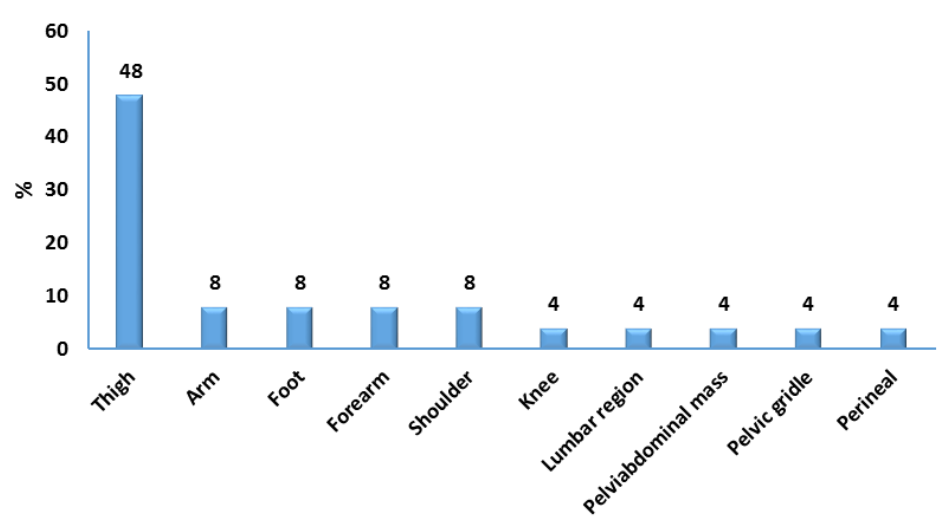

Figure 2: Site distribution of the study group. 


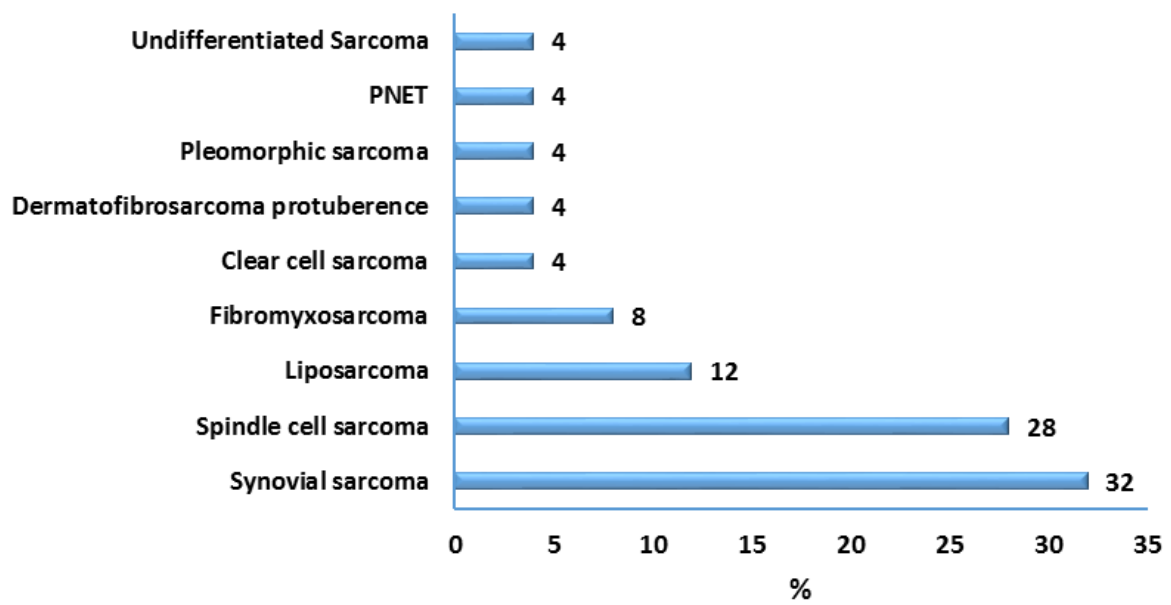

Figure (3) histopathological classification of the study group

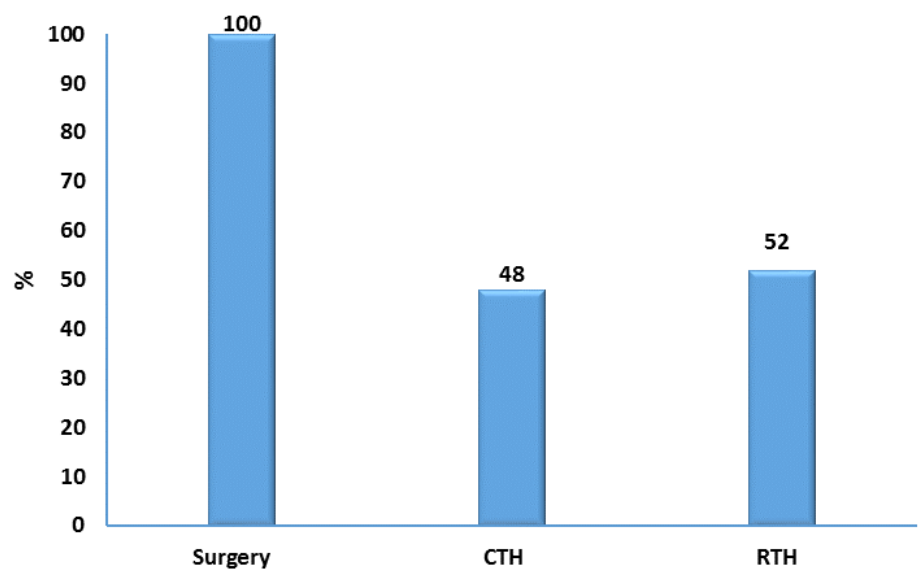

Fig 4: treatment patients received 


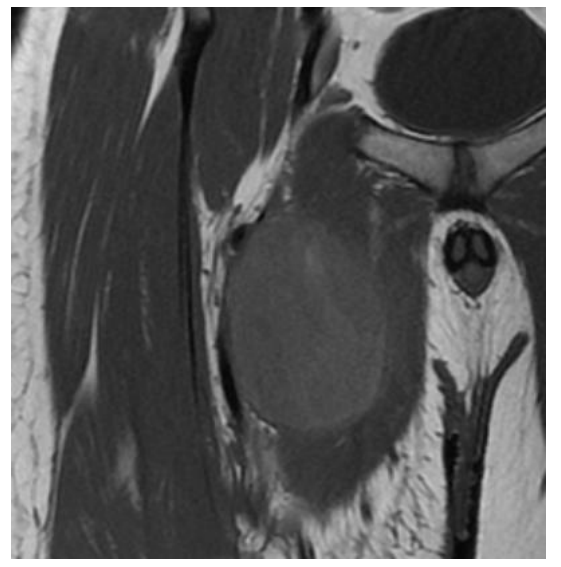

(a) Coronal T1

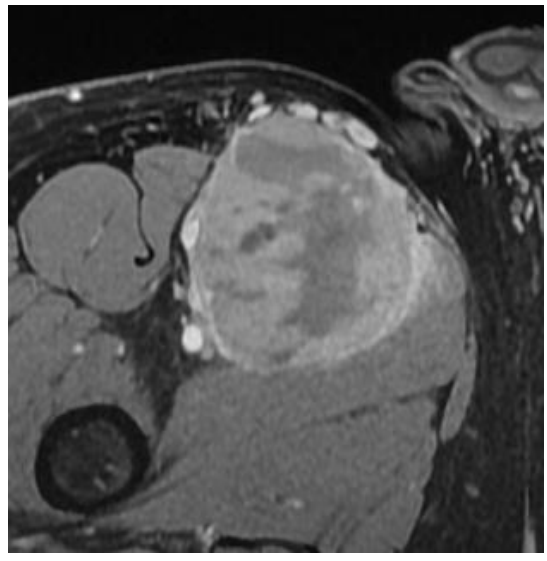

(c) Axial T1 Post contrast

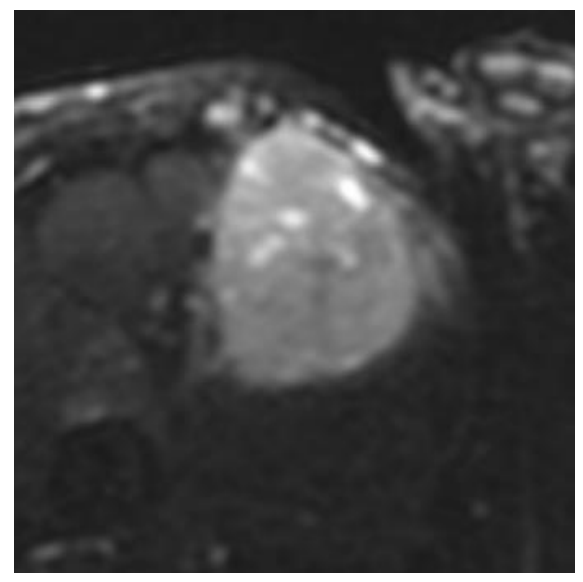

(e) DWI

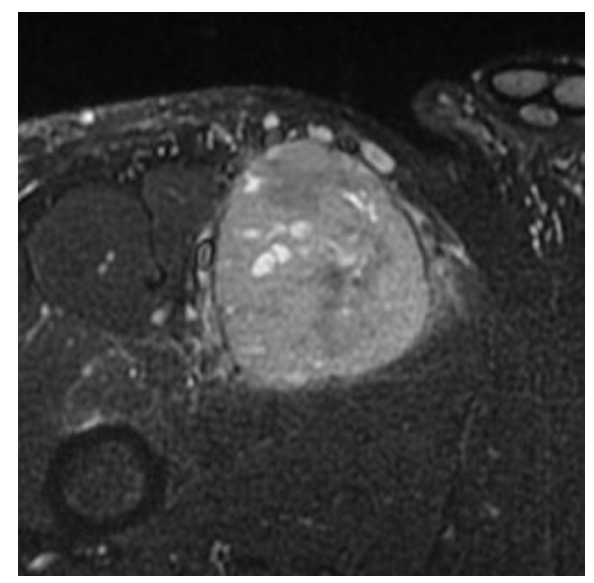

(b) Axial STIR

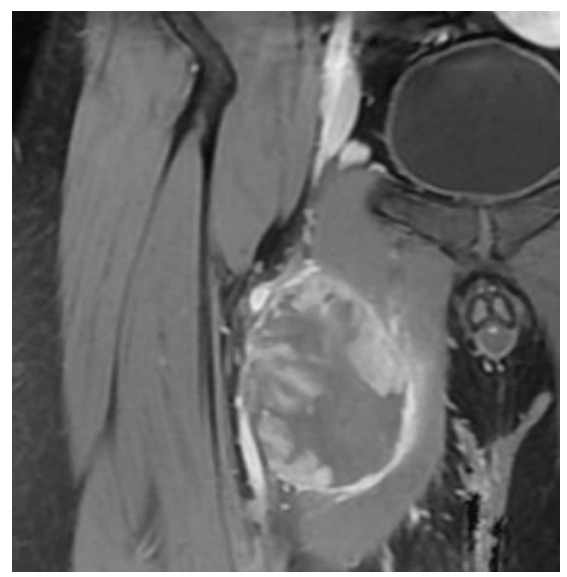

(d) coronal T1 post contrast

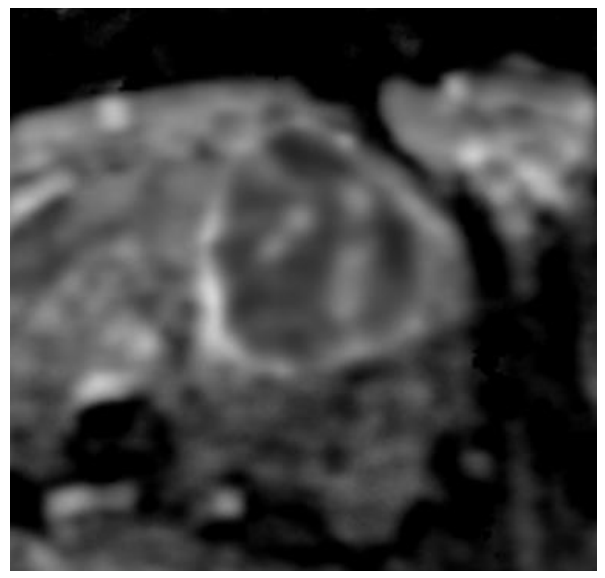

(f) $\mathrm{ADC}$

(Figure 5): (a) Coronal T1 showing soft tissue mass with iso to hypo intense signal (b)Axial STIR showing heterogeneous moderately hyper intense signal (c \& d) Axial and coronal T1 post contrast fat suppression with heterogeneous post Gadolinium enhancement (e) DWI most of the lesion show restriction (f) Corresponding ADC map with mean value of $0.5 \times 10^{-3} \mathrm{~mm} 2 / \mathrm{sec}$ 


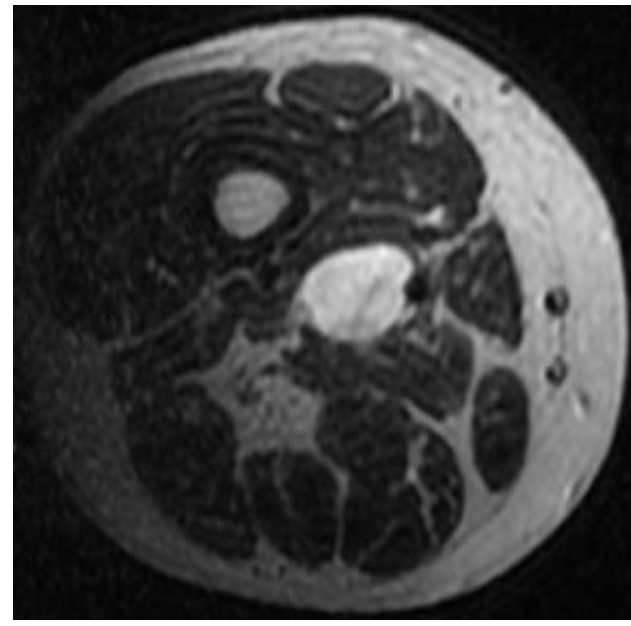

(a) Axial T2

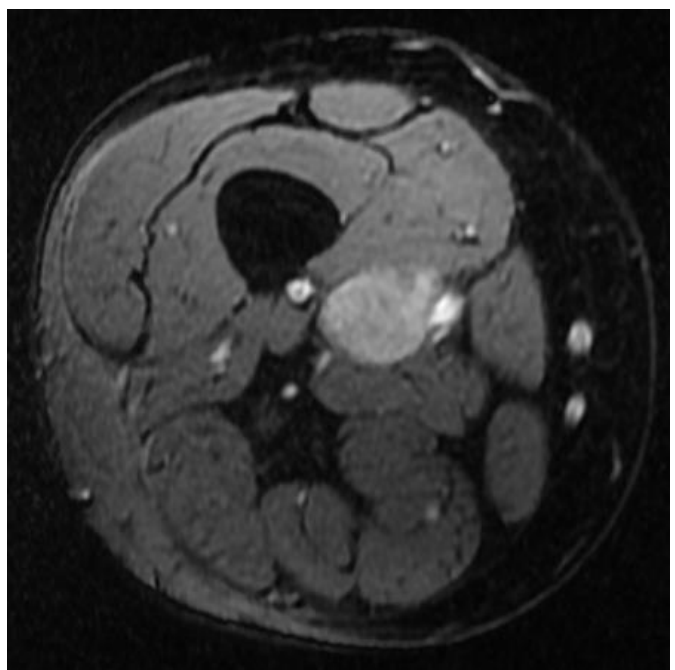

(c) Axial T1 post contrast

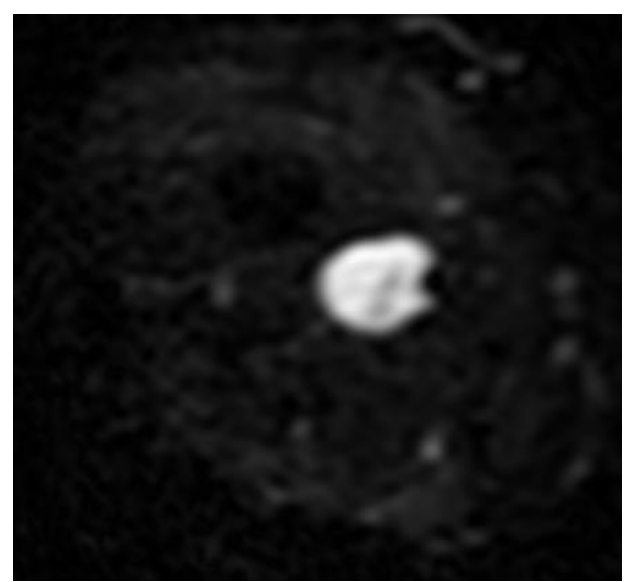

(e) DWI

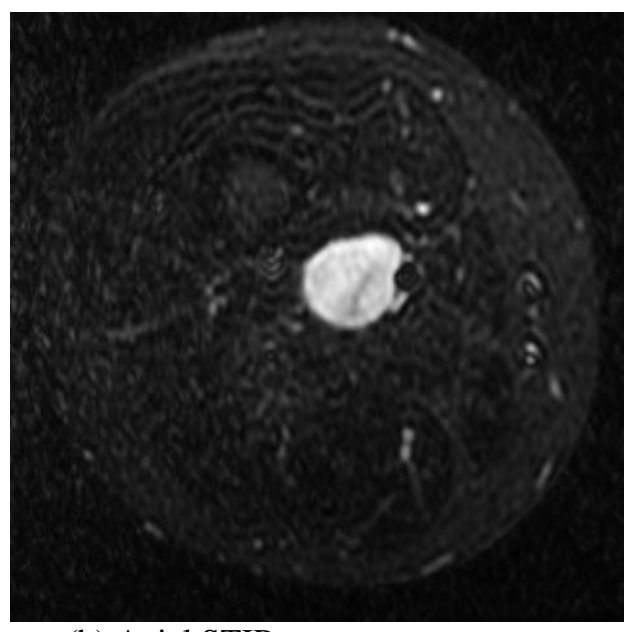

(b) Axial STIR

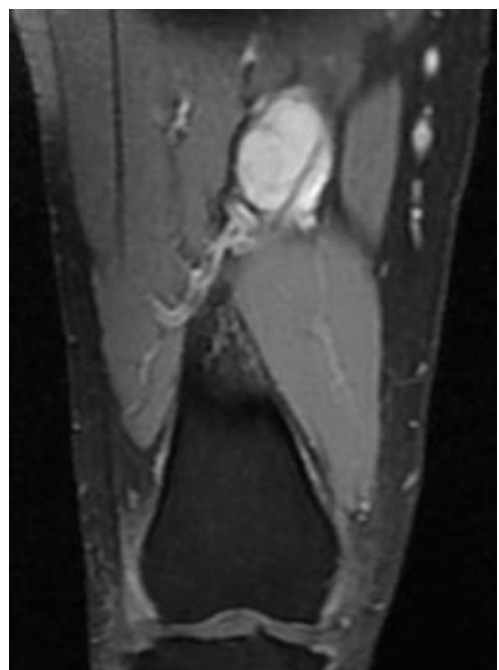

(d) coronal T1 post contrast

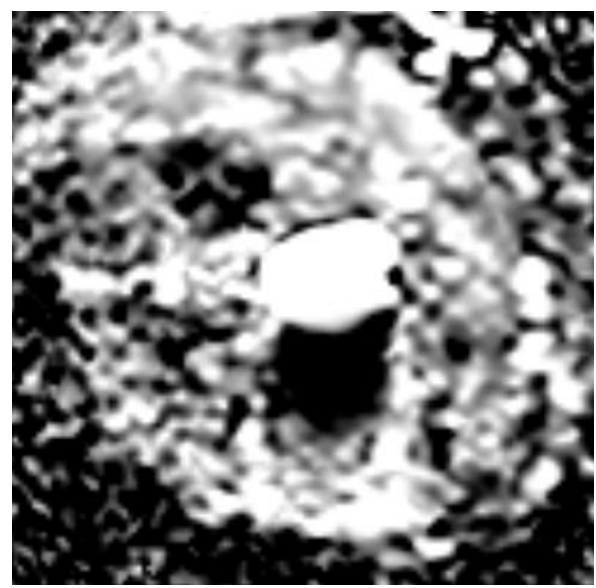

(f) ADC

(Figure 6): (a) Axial T2 showing soft tissue mass at the posterior aspect of the thigh with hyper intense signal (b) Axial STIR showing hyper intense signal (c \& d) Axial and coronal T1 post contrast fat suppression with 
Benha medical journal, vol. 39, special issue (radiology), 2022

heterogeneous post Gadolinium enhancement (e) DWI most of the lesion show no restriction (f) Corresponding ADC map with mean value of $2.0 \times 10^{-3} \mathrm{~mm} 2 / \mathrm{sec}$

Table (1): DWI with ADC value

Diffusion \& ADC

Restricted diffusion

n $(\%) \quad 40(80.0)$

ADC value $\left({\left.\mathrm{x} 10^{-3}\right)}^{-3} \quad\right.$ Median (range) $\quad 0.7(0.5-2.4)$

Table (2): follow up of the study group

Follow up findings

\begin{tabular}{lcc} 
Recurrence & Yes $\mathrm{n}(\%)$ & $26(52.0)$ \\
Metastasis & Yes $\mathrm{n}(\%)$ & $22(44.0)$ \\
Follow up (months) & Mean $\pm \mathrm{SD}$ & $13 \pm 5$ \\
\hline
\end{tabular}

Table (3) : Value of ADC which showed Recurrence

\begin{tabular}{|c|c|c|c|c|}
\hline & & \multicolumn{3}{|l|}{ Recurrence } \\
\hline & & Yes & No & $P$ value \\
\hline ADC value & Median (range) & $0.7(0.5-1.4)$ & $0.9(0.5-2.4)$ & 0.016 \\
\hline
\end{tabular}

\section{Discussion:}

Magnetic resonance imaging is indispensable in the evaluation of soft tissue tumors and become modality of choice. It offers improved soft tissue contrast when compared to other modalities ${ }^{(12)}$.

It was concluded in study done in $2018^{(13)}$ that addition of DWI \& quantitative ADC mapping to routine MR examination is advised for evaluation of soft tissue tumors especially in the inconclusive cases.
The DWI now is used in association with conventional MRI with the objective of improving diagnostic accuracy and treatment evaluation. DWI allows quantitative and qualitative analysis of tissue cellularity and cell membrane integrity and has been widely used for tumor detection and characterization to monitor treatment response ${ }^{(14)}$.

In the study in our hands, $80 \%$ of lesions showed restricted diffusion. Median ADC 
value was $0.7 \times 10^{-3} \mathrm{~mm}^{2} / \mathrm{sec}$ and ranged from 0.5 to $2.4 \times 10^{-3} \mathrm{~mm}^{2} / \mathrm{sec}$.

Our results matched with a study done in $2017^{(15)}$ which revealed ADC value of benign tumors which ranged between 2.21 $\times 10^{-3} \& 2.58 \times 10^{-3} \mathrm{~mm}^{2} / \mathrm{sec}$ and it was significantly higher than that of malignant soft tissue tumors which ranged between $0.90 \times 10^{-3} \& 1.82 \times 10^{-3} \mathrm{~mm}^{2} / \mathrm{sec}$, where the mean ADC value of all benign soft tissue tumors was $2.21 \pm 0.27 \times 10^{-3} \mathrm{~mm}^{2} / \mathrm{sec}$, while the mean ADC value of all malignant soft tissue tumors was $0.90 \pm 0.32 \times 10^{-3}$ $\mathrm{mm}^{2} / \mathrm{sec}$ with statistically significant difference $(\mathrm{p}<0.001)$.

It also matched another study published in $2015^{(16)}$ in which the mean ADC value of benign masses was $2.31 \pm 1.29 \times 10^{-3}$ $\mathrm{mm}^{2} / \mathrm{sec}$ and mean ADC value of malignant masses was $0.90 \pm 0.70 \times 10^{-3} \mathrm{~mm}^{2} / \mathrm{sec}$ with statistically significant difference $(\mathrm{p}<0.001)$.

Our results in that $\mathrm{ADC}$ has a role in predicting response therapy, being supported by a study done in $2019^{(17)}$ as in their study to evaluate neo-adjuvant therapy efficacy in accordance with response evaluation criteria in solid tumors (RECIST 1.1). ADC values in the non-progressive group were higher than those of the progressive group after neo-adjuvant treatment $(1.63 \pm 0.42$ vs. 1.24 $\pm 0.35)$ with $(\mathrm{p}<0.005)$. An increase in the
ADC value was not always associated with a reduction of tumor volume.

\section{Conclusion:}

Diffusion-weighted imaging (DWI) is a fast, non-contrast technique that is available and easy. DWI with apparent diffusion coefficient (ADC) mapping offers a quantitative method for soft tissue evaluation and has the value of regarding the cellularity of tumor. This article had highlighted the additive role of DWI in assessment of soft tissue sarcoma with emphasis on its prognostic value.

\section{References:}

1- Kolovich GG, Wooldridge AN, Christy JM, Crist MK, Mayerson JL, Scharschmidt TJ. A retrospective statistical analysis of high-grade soft tissue sarcomas. Med Oncol. 2012;29(2):1335-44.

2- Lahat G, Tuvin D, Wei C, Anaya DA, Bekele $\mathrm{BN}$, Lazar AJ ,et al. New perspectives for staging and prognosis in soft tissue sarcoma. Ann Surg Oncol. 2008; 15(10):2739-48.

3- Sbaraglia M, Dei Tos AP. The pathology of soft tissue sarcomas. Radiol Med. 2019;124(4):26681.

4- Fletcher CDM, Bridge JA, Hogendoorn P, Mertens F, eds. WHO Classification of Tumours of Soft Tissue and Bone. 4th ed. IARC WHO Classification of Tumours. Vol. 5. WHO Press; 2013.

5- Kransdorf MJ, Jelinek JS, Moser RP Jr, Utz JA, Brower AC, Hudson TM, et al . Soft-tissue 
masses: diagnosis using MR imaging. AJR Am J Roentgenol. 1989;153(3):541-7

6- Walker EA, Salesky JS, Fenton ME, Murphey MD. Magnetic resonance imaging of malignant soft tissue neoplasms in the adult. Radiol Clin North Am 2011;49: 1219-34.

7- Loizidez A, Widmann G, Freuis T, Peer S, Gruber H. Optimizing ultrasound-guided biopsy of musculoskeletal masses by application of an ultrasound contrast agent. Ultraschall Med. 2011;32(3):307-10.

8- Le Bihan D, Breton E, Lallemand D, Aubin ML, Vignaud J, Laval-Jeantet M. Separation of diffusion and perfusion in intra voxel incoherent motion MR imaging. Radiology. 1988;168: 497505.

9- Fayad LM, Jacobs MA, Wang X, Carrino JA, Bluemke DA.Musculoskeletal tumors: how to use anatomic, functional, and metabolic MR techniques. Radiology. 2012;265(2):340-56.

10- Benassi MS, Rimondi E, Balladelli A, Ghinelli C, Magagnoli G, Vanel D. The role of imaging for translational research in bone tumors. Eur $\mathrm{J}$ Radiol. 2011;82(12): 2115-23.

11-Messina C, Bignone R, Bruno A, Bruno A, Bruno F, Calandri M, et al. Diffusion-Weighted Imaging in Oncology: An Update. Cancers (Basel). 2020; 12(6):1493.

12- Goldblum JR, Weiss SW and Folpe AL. Enzinger and Weiss's Soft Tissue Tumors. Elsevier Health Sciences, London. pp:14-15, 2013.
13- Hassanien OA, Younes RL\& Dawoud RM. Diffusion weighted MRI of soft tissue masses: Can measurement of ADC value help in the

differentiation between benign and malignant lesions ?. The Egyptian Journal of Radiology and Nuclear Medicine, 2018;49(3):681-8.

14- Koh DM and Collins DJ. Diffusion-weighted MRI in the body: applications and challenges in oncology. Am. J. Roentgenol. 2007;188(6):162235.

15- Nassif MA, Abdul Rahim SA \&Hussien RZ. The Role of Diffusion-Weighted MRI in the Characterization of Musculoskeletal Soft Tissue Tumors. The Egyptian Journal of Hospital Medicine. 2017;69(2):1895-900.

16- Pekcevik Y, Kahya MO and Kaya A. Characterization of soft tissue tumors by diffusion weighted imaging. Iranian Journal of Radiology.2015;12(3):1-3.

17- Moustafa AFI, El Said SSMAS, Moustafa MA, Hussein MM \& Shokry AM. Diffusionweighted MR imaging diagnostic merits in the post-therapeutic assessment of musculoskeletal soft tissue sarcoma. Egyptian Journal of Radiology and Nuclear Medicine. 2019;50(1): 52.

To cite this article: Medhat M. Refaat, Shorouk Z. Abdelshafy, Asmaa H. Mohamed. The Prognostic Value of DWI MRI in the Diagnosis of Soft Tissue Sarcomas. BMFJ 2022; 39 (Radiology): 14-24. DOI: 10.21608/bmfj.2021.45987.1328 
Original article 
Benha medical journal, vol. 39, special issue (radiology), 2022 